\title{
Use of contrast ultrasonography to confirm correct peripheral intravenous access before general anesthesia
}

\author{
Antoine Lamblin, MD, MSc ${ }^{(10} \cdot$ Clément Derkenne, MD $\cdot$ Nicolas Alberti, MD
}

Received: 8 October 2017/Revised: 11 October 2017/ Accepted: 17 October 2017/Published online: 2 November 2017

(C) Canadian Anesthesiologists' Society 2017

\section{To the Editor,}

The use of ultrasonography is now well accepted for assisting in peripheral intravenous (PIV) access, particularly in patients with suspected difficult PIV insertion. $^{1,2}$ The use of contrast-enhanced ultrasonography may be of further benefit in confirming correct PIV placement and reducing the risk of drug extravasation during anesthetic induction.

We describe the case of a 68-yr-old woman (who consented to publication of this report) who was anesthetized for total knee arthroplasty. She was obese (body mass index $=47 \mathrm{~kg} \cdot \mathrm{m}^{-2}$ ), had type-II diabetes, and

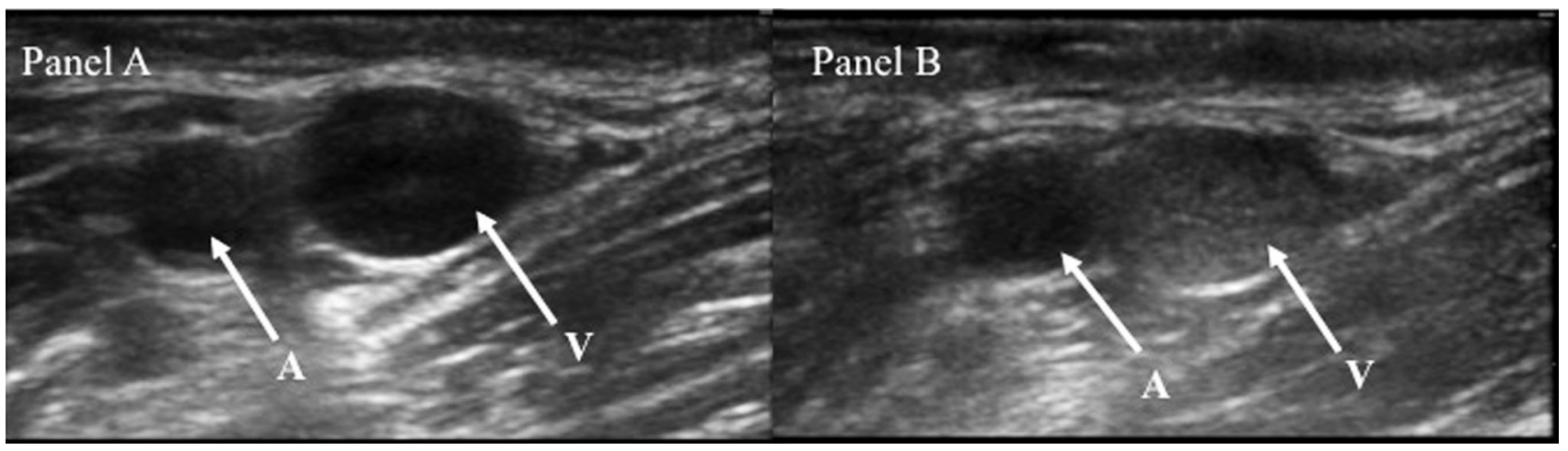

Figure Panel A) Two-dimensional (2D) ultrasonography (axial view) examination of the right axilla shows the right axillary vein (V) and artery (A). Panel B) Two-dimensional ultrasonography (axial

This work has never been presented at any meeting.

HIA Percy is the institution to which the work is attributed and is the source of financial support for the work.

A. Lamblin, MD, MSc ( $\varangle)$

Hôpital d'Instruction des Armées (HIA) Percy, Clamart, France e-mail: antoine.lamblin@hotmail.fr

\section{Derkenne, MD}

Fire Department of Paris, Paris, France

N. Alberti, MD

Centre hospitalier Alpes Léman, Contamine-sur-Arve, France view) of the left axilla again shows the left axillary vein (V) and artery (A), but this time with transit of echocardiographic contrast microbubbles in the left axillary vein

was known to have experienced previous difficulty with PIV insertion. An $18 \mathrm{G}$ PIV (BD Insyte ${ }^{\mathrm{TM}}$ Autoguard $^{\mathrm{TM}}$ Winged BD Vialon ${ }^{\mathrm{TM}}$, Sandy, UT, USA) was inserted into the right cephalic vein with ultrasonographic guidance, but the administration of $20 \mu \mathrm{g}$ sufentanil and $100 \mathrm{mg}$ propofol appeared to have no systemic effect. Echocardiographic contrast material $(9.5 \mathrm{~mL}$ of $0.9 \%$ saline mixed with 0.5 $\mathrm{mL}$ air) was then again injected via the same PIV, but twodimensional ultrasonography (high-frequency linear vascular probe, LOGIQ $^{\mathrm{TM}} \mathrm{e}$ Ultrasound System; GE Healthcare $^{\mathrm{TM}}$, Milwaukee, WI, USA) showed no transit of microbubbles at the level of the right axillary vein 
(Figure, panel A). This observation suggested that the intravenous catheter must have been dislodged during taping of the PIV cannula and was now in an extravascular position. Accordingly, a second PIV cannula was inserted into the left arm with ultrasonographic guidance. Contrast ultrasonography, performed before intravenous induction, showed passage of the microbubbles at the left axillary vein, thus confirming correct intravascular placement of the PIV (Figure, panel B). The patient was then successfully induced with $200 \mathrm{mg}$ propofol, and the surgery proceeded uneventfully.

The initial anesthetic failure due to sufentanil and propofol extravasation might have been avoided if contrast ultrasonography had been performed initially, before anesthetic drug injection. This case emphasizes the potential utility of ultrasonography, not only for helping with the initial insertion of the PIV line but also confirming its correct placement prior to drug injection.
Conflicts of interest None declared.

Editorial responsibility This submission was handled by Dr. Hilary P. Grocott, Editor-in-Chief, Canadian Journal of Anesthesia.

\section{References}

1. Gregg SC, Murthi SB, Sisley AC, Stein DM, Scalia TM. Ultrasounded-guided peripheral intravenous access in the intensive care unit. J Crit Care 2010; 25: 514-9.

2. Benkhadra M, Collignon M, Fournel I, et al. Ultrasound guidance allows faster peripheral IV cannulation in children under 3 years of age with difficult venous access: a prospective randomized study. Paediatr Anaesth 2012; 22: 449-54. 